\title{
Atendimento Escolar Hospitalar: Trajetória pela Fundamentação Científica e LegaL ${ }^{1}$ \\ Hospital School Assistance: Ways Throughout SCIENTIFiC and LeGAL BAses
}

\author{
Eneida Simóes da FONSECA² \\ Camila Camilozzi Alves Costa de Albuquerque ARAÚJO3 \\ Carla Bronzo LADEIRA ${ }^{4}$
}

\begin{abstract}
RESUMO: O atendimento escolar hospitalar é normatizado por legislação própria há quase duas décadas. Dessa forma, o objetivo deste artigo foi analisar a trajetória científica e legal dessa temática, a partir de estudo comparado entre os artigos publicados na Revista Brasileira de Educação Especial que tratam especificamente desse assunto, os resultados dos encontros nacionais promovidos, os informativos semestrais divulgados e alguns trabalhos acadêmicos recentes relacionados ao tema. A técnica de pesquisa utilizada foi a pesquisa bibliográfica e documental, e a análise proposta foi a de conteúdo. Os resultados apontam que essa área do conhecimento se fundou a partir de pesquisas que, à época, mesmo que incipientes, nortearam o que se delimitaria como a essência do atendimento escolar ao doente. Apesar do aumento da oferta desse tipo de ensino, ela não necessariamente está circunscrita à escolarização no hospital, demonstrando entendimento diverso do que preconizam as normativas legais para esse serviço. Os encontros nacionais mantêm a discussão, mas também se projetam para temáticas que náo dialogam diretamente com a proposta de escolarização no hospital, mas com outros aspectos relacionados à vida do doente. Os informativos semestrais focam mais especificamente nessa área de atuação. Estes divulgam estudos, legislaçōes, eventos pertinentes, assim como aproximam os interessados por essa modalidade educacional. Considerando-se também a realidade dessa escolarização em outros países, é possível afirmar que o reconhecimento e respeito do direito de escolaridade do doente fazem com que esse serviço seja oferecido com a jurisprudência e a qualidade necessárias para o cumprimento de suas atribuiçóes junto ao alunado doente.
\end{abstract}

PALAVRAS-CHAVE: Educação Especial. Escola em hospital. Garantia de atendimento escolar. Legislaçâo.

ABSTRACT: Hospital school assistance has been regulated by its own legislation for almost two decades. Thus, the objective of this paper was to analyze the scientific and legal bases of this subject using a comparative study between the papers published in the Brazilian Journal of Special Education that deal specifically with this theme, the results of national meetings promoted, the biannual newsletters disseminated and some recent academic papers related to the topic. The research technique used was the bibliographical and documentary research, and the proposed analysis was the content analysis. The results point out that this area of knowledge was based on research that at the time, even if incipient, guided what would be delimited as the essence of school assistance to the patient. Despite the increase in the supply of this type of education, it is not necessarily restricted to schooling in the hospital, demonstrating a different understanding of what the legal regulations for this service prescribe. The national meetings continue the discussion, but they are also projected for themes that do not directly dialogue with the proposal of schooling in the hospital, but with other aspects related to the life of the patient. Biannual newsletters focus more specifically on this area. They disseminate studies, legislation, relevant events, and bring the interested people in this educational modality closer. Considering also the reality of this schooling in other countries, it is possible to affirm that the recognition and respect of the right to schooling of the patient make this service be offered with the jurisprudence and the quality necessary for the fulfillment of its attributions with the sick pupils.

KEYWORDS: Special Education. School in hospital. Guarantee of School Assistance. Legislation.

\footnotetext{
${ }^{1}$ http://dx.doi.org/10.1590/S1413-65382418000400008

${ }^{2}$ Docente da Faculdade de Educação da Universidade do Estado do Rio de Janeiro (EDU-UERJ), Rio de Janeiro - RJ, Brasil. eneida@uerj.br.

${ }^{3}$ Mestre em Administração Pública e Pedagoga do Centro Pedagógico da Universidade Federal de Minas Gerais (UFMG), Belo Horizonte-MG, Brasil. camila.camilozzi@gmail.com.

${ }^{4}$ Docente da Escola de Governo da Fundação João Pinheiro, Belo Horizonte - MG, Brasil. cbronzo@gmail.com.
} 


\section{INTRODUÇÃo}

A busca por estudos sobre o atendimento escolar em ambiente hospitalar publicados na Revista Brasileira de Educação Especial, ao longo de seus 25 anos de existência, identificou apenas quatro artigos sobre esse assunto. Nesse sentido, a análise do caminho tomado pelo atendimento escolar hospitalar à luz dessas publicaçóes inspirou a procura por outros estudos que respaldassem os resultados e as consideraçóes advindos das pesquisas constantes desse periódico em particular. Assim, o objetivo do presente texto é apontar a relação de aspectos da produção científica e legal na trajetória dessa área específica do conhecimento.

Para traçar esse percurso, também foram conduzidas análises dos estudos sobre as possíveis contribuiçóes para a área do atendimento escolar hospitalar das diversas ediçóes dos encontros nacionais (Fonseca, 2016) e dos informativos semestrais (Fonseca, 2017), ambos voltados à temática do atendimento escolar hospitalar.

Buscando ampliar a discussão, somaram-se ao estudo dos artigos da Revista Brasileira de Educação Especial as publicaçôes iniciais sobre o mapeamento do atendimento escolar hospitalar (Fonseca, 1999) e sobre o papel da escola para o alunado doente (Fonseca \& Ceccim, 1999). Tal dinâmica conduziu também referendar alguns trabalhos acadêmicos que abordam a fundamentação legal para a implantação e a implementação do serviço de escolarização durante a enfermidade no contexto brasileiro (Araújo, 2017; Pacheco, 2017) e nas realidades canadense (Fonseca, 2013) e espanhola (Menezes, 2018).

A técnica de investigação utilizada foi a pesquisa bibliográfica e a pesquisa documental. De acordo com Lakatos e Marconi (2001, p. 157), a pesquisa bibliográfica "é um apanhado geral sobre os principais trabalhos já realizados, revestidos de importância, por serem capazes de fornecer dados atuais e relevantes relacionados com o tema". Para este texto, foram consultados documentos, artigos de periódicos e trabalhos de Pós-Graduação sobre a temática em questão.

Já a pesquisa documental compreende a "busca de informaçôes em documentos que não receberam nenhum tratamento científico, como relatórios, reportagens de jornais, revistas, cartas, filmes, gravaçóes, fotografias, entre outras matérias de divulgação" (Oliveira, 2007, p. 69). Dessa forma, foram consultados os anais dos encontros nacionais e as edições dos informativos semestrais sobre o atendimento escolar hospitalar.

Os dados oriundos dos materiais bibliográficos e das legislaçóes relacionadas à temática do atendimento escolar hospitalar foram submetidos à análise de conteúdo (Bardin, 1979). A metodologia proposta permite "estabelecer uma correspondência entre o nível empírico e teórico, de modo a assegurar-nos que o corpo de hipóteses é verificado pelos dados do texto" (Bardin, 1979, p. 69). Dessa forma, as publicaçóes foram classificadas pelo foco central das investigaçóes conduzidas, seus resultados e as consideraçóes feitas acerca da fundamentação legal do atendimento escolar no ambiente hospitalar. As legislaçóes foram classificadas segundo sua pertinência direta ou indireta com o atendimento escolar hospitalar. Posteriormente, as classificaçôes foram analisadas e, sobre elas, tecidas reflexóes. 


\section{Desenvolvimento}

A apresentação da análise dos materiais relacionados ao atendimento escolar hospitalar que compóem este trabalho foi dividida em três partes, a saber: sobre as publicaçóes na Revista Brasileira de Educação Especial, sobre os encontros nacionais e informativos semestrais e sobre as produçóes acadêmicas outras e legislaçóes, conforme detalhado a seguir.

\subsection{PublicaÇóes sobre atendimento escolar hospitalar na ReVista Brasileira de EducAÇÃo EsPECIAL}

São quatro os artigos sobre o atendimento escolar hospitalar presentes na Revista Brasileira de Educação Especial ao longo de seus 25 anos de existência, conforme detalhamento a seguir.

O primeiro deles, o trabalho de Fonseca (2002), trata da implantação e da implementação do atendimento escolar no ambiente hospitalar. $\mathrm{O}$ estudo apresenta e discute os resultados de coleta de dados por questionários que foram endereçados aos serviços dessa modalidade de ensino. No âmbito da situação administrativa, dos 74 atendimentos escolares em ambiente hospitalar considerados no estudo, para 34\% deles está presente a existência de convênio formal entre o serviço de saúde e a Secretaria de Educação local. Acrescenta-se que $36 \%$ desses serviços funcionam como anexos de escolas regulares localizadas geograficamente próximas do hospital para que seja mantida a situação funcional dos professores cedidos para o atendimento escolar hospitalar. Os demais serviços dessa modalidade funcionam de modo diverso, seja como proposta vinculada ao setor de educação ou saúde oficiais, ou como projeto de instituição de Ensino Superior ou ONG e, nesses casos, o atendimento escolar não é necessariamente feito por professores efetivos ou contratados, mas por estagiários, bolsistas ou mesmo voluntários. No que se refere aos documentos legais, são citados o Estatuto da Criança e do Adolescente (Lei Federal no 8.069, 1990), a resolução sobre os Direitos da Criança e do Adolescente Hospitalizados (Resolução no 41, 1995), as Diretrizes Nacionais para a Educação Especial na Educação Básica (Resolução CEB/CNE nº 2, 2001). Também é feita referência ao documento Classe Hospitalar e Atendimento Pedagógico Domiciliar (2002), que foi publicado na mesma época do estudo aqui analisado.

As considerações de Fonseca (2002) citam não apenas o aumento do quantitativo de hospitais com escolas em relação à pesquisa inicial sobre o tema (Fonseca, 1999), mas, também, de eventos e publicaçóes voltadas a essa área. A autora salienta a necessidade de observância ao documento específico sobre este atendimento (Classe hospitalar e atendimento pedagógico domiciliar, 2002) para que o serviço tenha estrutura administrativa, física e material necessárias para garantir a qualidade da oferta à clientela doente.

No segundo artigo levantado, Barros, Gueudeville e Vieira (2011) traçam, na revisão de literatura conduzida, o perfil da publicação científica brasileira entre 1997 e 2008 acerca dessa temática específica, que, de acordo com a terminologia utilizada pelo Ministério da Educação (Resolução CEB/CNE n 2, 2001), é denominada classe hospitalar. $\mathrm{O}$ estudo identifica tanto trabalhos fundamentados metodologicamente quanto os que discorrem sobre experiências vivenciadas no ambiente hospitalar; relata o aumento contínuo das publicaçóes sobre o assunto ao longo dos anos e que, em geral, foram acolhidas em periódicos do campo da Educação, embora seja um assunto de abrangência multidisciplinar. Entretanto, salienta para 
o fato de que a grande maioria dessas publicações não é de fácil acesso aos interessados pelo tema por terem sido publicadas em periódicos não indexados em bases de dados bibliográficos especializadas. Isso, segundo as autoras, também implica no questionamento da qualidade das publicaçóes que, em geral, afirmam a existência dessa modalidade de atendimento sem criticar ou problematizar tal serviço. Acrescentam que, para o enriquecimento teórico-metodológico dessa área do conhecimento, os estudos feitos não fiquem circunscritos apenas à garantia do direito de educação dessa parcela da população, mas investiguem e evidenciem as mudanças necessárias para uma atuação profissional qualificada na escola do ambiente hospitalar. Não são feitos comentários sobre ou relaçóes com a legislação que trata do assunto.

O terceiro texto encontrado (Saldanha \& Simóes, 2013) fez análises de publicaçóes online (de 1996 até 2010) sobre a educação escolar hospitalar, categorizando-as em concepçôes e significados; relação educação-saúde; aspectos pedagógicos e didático-curriculares; histórico e fundamentos legal; e formação profissional. Foram feitas reflexões sobre a crescente produção acadêmica nessa temática e também da urgência de ampliação de políticas públicas que reforcem o direito de educação do doente no hospital ou domicílio. As autoras pontuam a alocação de professores efetivos nas escolas em hospitais e a relevância de acompanhar o aluno que esteve doente quando do retorno à sua escola de origem.

O estudo de Xavier, Araújo, Reichert e Collet (2013), quarto artigo publicado na revista, resulta de uma revisão integrativa de literatura sobre a produção do conhecimento em saúde e em educação relacionadas com a escola no hospital. As autoras classificaram as publicaçóes segundo os conteúdos enfocados pelos autores, a saber: aspectos administrativo-institucionais; relaçóes entre atendimento escolar e hospitalização; e prática pedagógica na escola hospitalar. Os resultados ratificam a validade do atendimento escolar no hospital e referenciam as diretrizes que tratam dessa modalidade de ensino (Resolução CEB/CNE nº 2, 2001). Pontuam que o atendimento hospitalar "não desmereça o cuidado com a educação" (Xavier et al., 2013, p. 621) e que a atuação docente é de extrema importância e não deve ser confundida "com as açóes do psicólogo, do assistente social ou até mesmo do recreador" (Xavier et al., 2013, p. 621). Embora tendo formação e atuando no âmbito da saúde, as autoras perceberam haver "lacunas importantes em relação às informaçóes oficiais" sobre a escolarização do indivíduo hospitalizado "para conhecer a dimensão e a distribuição dessas atividades no Brasil e no mundo” (Xavier et al., 2013, p. 621).

Nos quatro artigos, a terminologia classe hospitalar é usada no sentido de referenciar o atendimento escolar hospitalar, embora, nas palavras-chave de um deles, conste outra expressão utilizada para denominar essa área do conhecimento, mas que, no caso específico, não necessariamente diz respeito ao acompanhamento da escolaridade da clientela doente. Tais estudos apontam a necessidade de investigaçóes críticas e problematizadoras da realidade do atendimento escolar no hospital para que ele implique açóes calcadas na relação teoria-prática fortalecidas por fundamentação legal também respaldada em pesquisas, garantindo, assim, a excelência do serviço prestado e não apenas a atenção ao direito de escolaridade do doente.

As publicações disponibilizadas na Revista Brasileira de Educação Especial e aqui analisadas evidenciam não apenas o conhecimento sobre, mas também a relevância de se dispor de construtos legais que assegurem o direito de escolaridade para a população doente. Mesmo 
assim, buscamos outras publicaçóes científicas e legais, relacionadas ou específicas, que apontem possíveis contribuições à trajetória dessa modalidade de ensino. Delas tratamos a seguir.

\subsection{ENCONTROS E INFORMATIVOS ESPECÍFICOS PARA O ATENDIMENTO ESCOLAR HOSPITALAR}

Eventos e publicações assim como capacitação no âmbito da Graduação ou da PósGraduação podem contribuir para com a qualificação profissional (Libâneo \& Pimenta, 1999). Para esses autores, o acúmulo de informaçóes e de conhecimentos pode reforçar uma área específica de atuaçáo. Nesse sentido, aqui refletimos sobre possíveis contribuiçóes para a área de atendimento escolar hospitalar dos estudos sobre os Encontros Nacionais (Fonseca, 2016) e sobre os Informativos Semestrais (Fonseca, 2017) que são específicos para essa temática.

$\mathrm{Na}$ referência aos encontros nacionais dirigidos a essa modalidade de ensino em particular, estes têm acontecido de modo itinerante e, em geral, bianualmente desde o ano 2000, quando teve sua primeira e, até então, inédita edição contemplando esse conteúdo específico. $\mathrm{O}$ Encontro inaugural aconteceu no Rio de Janeiro (RJ). No presente ano, o $10^{\circ}$ Encontro Nacional sobre Atendimento Escolar Hospitalar teve como sede a cidade de Salvador (BA) que, anteriormente (2004), sediou a sua terceira edição. As demais sedes foram as cidades de Goiânia (GO), em 2002; Porto Alegre (RS), em 2005; Curitiba (PR), em 2007 e 2015; Niterói (RJ), em 2009; Belém (PA), em 2012; e São Paulo (SP), em 2014. Fonseca (2016) analisou os anais (impresso ou em CD) de sete das nove edições do referido evento. Infelizmente, as compilaçóes da segunda (Goiânia em 2002) e da quarta (Porto Alegre em 2005) ediçóes do Encontro não foram concluídas e, por isso, tais documentos não estão disponíveis.

De acordo com a autora, por conta da diversidade de olhares sobre as demandas dos doentes e dos grupos de profissionais que, nas distintas cidades brasileiras, se responsabilizam por sediar, organizar e realizar os encontros, a manutenção textual dos objetivos do evento não tem garantido que tais ediçôes, de fato, se refiram prioritariamente à atenção escolar ao doente. Por exemplo, humanização, educação em saúde e brinquedotecas são abordagens presentes ao longo das ediçóes dos encontros nacionais. Sem dúvida que tais assuntos podem ser tratados nesse evento específico, mas preferencialmente contextualizados ou em interlocução com a escolarização no ambiente hospitalar, o que, infelizmente, não tem sido o caso. No que diz respeito à fundamentação legal relativa a essa área de atendimento, apresentações e, até mesmo, reuniôes são pautadas na programação e realizadas nos encontros, mas, em geral, resultam incipientes porque a diversidade de entendimentos quanto a essa modalidade de ensino dificulta a delimitação do escopo dessa atividade, tornando complexa a formulação de respaldo legal pertinente.

Quanto aos informativos semestrais ${ }^{5}$, desde sua primeira edição em dezembro do ano 2000, se mantém o objetivo de divulgar aos interessados o que acontece no que se refere às pesquisas, às publicaçóes, às legislaçóes e à agenda de eventos sobre o atendimento escolar hospitalar, além da atualização do mapeamento de escolas em hospitais. As informaçóes que compóem cada edição do informativo são obtidas por meio da interlocução com pessoas inte-

\footnotetext{
${ }^{5}$ A primeira edição (impressa) foi enviada para 230 pessoas, em geral participantes do $1^{\circ}$ Encontro. Atualmente, a edição é virtual e bilíngue (português e inglês) e enviada, no caso da última edição (dezembro/2017), para 1.225 contatos de e-mail nacionais e 240 internacionais.
} 
ressadas no atendimento escolar hospitalar e que acessam o site Atendimento Escolar Hospitalar ${ }^{6}$ ou fazem contato por e-mail ${ }^{7}$, telefone ou presencialmente nos eventos ou em reunióes outras. Ao longo do semestre, as informaçóes são compiladas, editadas e divulgadas quando da ocasião de uma nova edição do informativo, em geral, nos meses de junho e dezembro de cada ano. Detalhes dos aspectos físicos das ediçóes ao longo dos anos podem ser obtidos no trabalho de Fonseca (2016), não sendo pertinente reproduzi-los aqui.

De acordo com o estudo de Fonseca (2017), o informativo completou 18 anos de ediçôes consecutivas em 2017. Foram analisadas todas as 35 ediçóes do referido documento (de dezembro/2000 até dezembro/2017). Os resultados mostram os informativos semestrais circunscritos à atenção escolar hospitalar e, assim sendo, veiculam conteúdos especificamente relacionados ao tema. $\mathrm{O}$ respaldo legal pertinente tem sido veiculado em diversas ediçóes do informativo. Por exemplo, os estados do Acre, Bahia, Pará, Paraná, Rio Grande do Norte e São Paulo formularam e divulgaram suas legislaçóes sobre o atendimento escolar hospitalar.

Como o acesso ao informativo não implica qualquer custo financeiro, já que é disponibilizado por e-mail, também é democrático na divulgação dos contatos daqueles que contribuem com as matérias apresentadas, facilitando a interlocuçáo direta entre os interessados. Fonseca (2017) acrescenta que, considerando-se o fato de não ter havido mudança do responsável pela compilação e edição das seguidas edições da publicação, é perceptível tanto a manutenção do foco das ediçóes quanto o fomento ao intercâmbio entre os leitores, contribuindo para com a dinâmica dessa área específica do conhecimento.

Refletindo sobre a contribuição que ambos, encontros nacionais e informativos semestrais, agregam à área do atendimento escolar hospitalar, alguns aspectos podem ser discutidos. A dimensão territorial brasileira torna os deslocamentos demandantes de tempo e, juntamente à falta de suporte financeiro para as viagens, são fatores comprometedores da participação de professores da sala de aula no hospital nos encontros sobre esse tema. Conjuntamente, há os trâmites burocráticos a que os professores devem se submeter e que, não poucas vezes, os impossibilitam de deixar a sala de aula ${ }^{8}$ por alguns dias para participar de um evento. Outro aspecto dificultador é o fato de que, cada vez mais corriqueiramente, o período de divulgação de cada nova edição do encontro (entre a confirmação de realização e a data de acontecimento) é de apenas alguns meses de antecedência. Isso compromete o tempo necessário que o professor precisa para articular todos os trâmites de sua participação no evento. Em contrapartida, na medida em que os encontros não têm local fixo de ocorrência, seu caráter itinerante pelo país se configura em oportunidade de participação dos professores que estejam no local sede de cada edição ou nas suas proximidades.

A cada nova edição do encontro, assuntos além dos especificamente pertinentes ao atendimento escolar hospitalar têm sido inseridos na programação. Como já dito, isso seria enriquecedor se fosse vivenciado um diálogo apropriado entre os profissionais que apresentam tais temáticas e aqueles que atuam no ambiente escolar hospitalar. Assim, como em muitos outros eventos no âmbito da educação (e, infelizmente, em outras áreas do conhecimento também),

\footnotetext{
${ }^{6}$ Disponível na página: www.escolahospitalar.uerj.br

7 escolahospitalar@uerj.br

${ }^{8}$ Em geral, os alunos ficam sem aulas na ausência do professor por não ocorrer sua substituição em tal período.
} 
o encontro parece prestar-se para apenas divulgar a produção acadêmica dos participantes sem, necessariamente, acrescer conteúdo relevante à área de escolarização do doente.

No que diz respeito aos informativos semestrais, estes têm mantido foco específico no atendimento escolar hospitalar. Assim, o professor da escola no hospital tem acesso a conteúdos mais pertinentes à sua atuação, podendo ou conseguindo introduzi-los na sua formação profissional específica. A divulgação de legislações implementadas em estados distintos do Brasil pode despertar ou motivar o professor da escola no hospital a averiguar a situação de seu atendimento nesse aspecto ou solicitar que fundamentação semelhante seja conduzida em sua cidade ou estado em benefício dessa modalidade de atendimento.

A postura democrática do informativo, inclusive na divulgação dos contatos, estimula a interação direta entre os pares. Assim, se o professor desejar aprofundar-se sobre as informaçóes lidas na publicação, poderá fazê-lo com autonomia ou, tendo problemas, contatar o e-mail do informativo (escolahospitalar@uerj.br) para mediar a interlocução ou para obter outros esclarecimentos sobre a informação.

Concluímos parecer haver significativas dificuldades para que os professores das escolas em hospitais participem das ediçóes do Encontro Nacional além do fato de que esses eventos estejam mais abrangentes nas abordagens tratadas. Já os informativos parecem mais focados na atenção escolar hospitalar e, assim sendo, veiculam matérias mais específicas para o professor que atua nesse tipo de ensino. Isso não quer dizer que os informativos sejam mais relevantes na formação do professor do ambiente escolar hospitalar do que os encontros. Talvez, em comparação com os encontros (que são presenciais), os leitores do informativo (que é virtual) tenham contato mais direto com seus interlocutores.

\subsection{APORTES DE PRODUÇÓES ACADÊMICAS OUTRAS E DE LEGISLAÇÓES PARA O ATENDIMENTO ESCOLAR HOSPITALAR}

$\mathrm{Na}$ medida em que se delineou a situação brasileira do atendimento escolar hospitalar (Fonseca, 1999) e, concomitantemente, se demonstrou a relevância da escolarizaçáo no contexto do hospital (Fonseca \& Ceccim, 1999), tais resultados ${ }^{9}$ estimularam, como detalhado no item anterior, tanto o planejamento de encontro específico nessa área quanto a veiculação do informativo semestral que se configuraram como desdobramentos naturais.

É importante ressaltar que os estudos de Fonseca (1999) e de Fonseca e Ceccim (1999) contribuíram tecnicamente para a elaboração, no âmbito Federal, do, até então, único documento oficial (Resolução $\mathrm{CEB} / \mathrm{CNE} n^{\circ} 2$, 2001) a abordar especificamente essa modalidade de ensino, mesmo que a mantendo vinculada à Educação Especial. Não bastante, também fomentaram a construção das estratégias e das orientações para a implantação e implementação do atendimento escolar hospitalar e domiciliar (Classe hospitalar e atendimento pedagógico domiciliar, 2002), documento este que, na versão preliminar, foi submetido ao escrutínio das secretarias de educação dos estados e das capitais e de instituições de Ensino Superior e profissionais atuantes e/ou estudiosos desse tipo de ensino. Quando da elaboração da versão final do

\footnotetext{
${ }^{9}$ Esses estudos não foram subsidiados por órgãos governamentais, instituiçōes de ensino ou agências de fomento. À época, nem mesmo se cogitou obter aporte financeiro para realizá-los.
} 
referido documento, constou nele o nome de todas as pessoas e/ou entidades que responderam e encaminharam suas observações sobre ele. Ambos os documentos nortearam a formulação de mudanças necessárias para que o atendimento escolar ao doente se ampliasse e melhor atendesse a sua clientela específica.

A seguir, citamos trabalhos acadêmicos que, em diferentes contextos geográficos, referendam o papel da fundamentação legal na implantação e na implementação do atendimento escolar hospitalar.

Tendo como um dos focos de estudo a análise do processo de implantação e de desenvolvimento do atendimento escolar hospitalar na cidade de Curitiba (PR), no período entre 1988 e 2015, a pesquisa de Pacheco (2017) elegeu como embasamento o resgate do histórico desse tipo de atendimento no referido município e documentos legais federais e locais norteadores e pertinentes. Nesse sentido, seu trabalho contempla aspectos que são complementares à análise contida nos itens anteriores do presente texto.

De acordo com Pacheco (2017), no ano de 1988, formulou-se a proposta inicial de atendimento escolar ao doente hospitalizado em Curitiba. A proposta foi respaldada por Decreto Federal (Decreto-Lei no 1.044, 1969) "sobre o tratamento excepcional para os alunos portadores das afecções”. Estabeleceu-se, então, parceria da prefeitura local com quatro hospitais, a saber: Hospital Pequeno Príncipe, Hospital Cesar Pernetta, Hospital Erasto Gaertner e Hospital de Clínicas. A prefeitura cedeu quatro professoras para atuarem como recreacionistas nesses hospitais e, nesse sentido, eram desenvolvidas apenas atividades lúdicas e recreativas com os doentes. Concomitantemente, Mugiatti (1989) propóe a escolarização da clientela doente do Hospital Pequeno Príncipe e do Hospital Cesar Pernetta, denominada de Projeto Mirim de Hospitalização Escolarizada. Essa iniciativa foi considerada e seguida também pelos outros dois hospitais. Assim, a partir de 1989, o órgão educacional do município formaliza termo de cooperação técnica com esses hospitais para a cessão de professoras para o acompanhamento da escolaridade da clientela doente. De acordo com Pacheco (2017), a expressão atendimento escolar hospitalar foi citada pela primeira vez no ano de 2006 nas Diretrizes Curriculares para a Educação Municipal de Curitiba. A autora pontua que, na atualidade, o serviço de atendimento escolar hospitalar da Secretaria Municipal de Educação (SME) de Curitiba é denominado Programa de Escolarização Hospitalar (PEH) e caracteriza-se por perseguir a continuidade da escolarização da clientela doente, ratificando o preceito constitucional de todos à educação, como um direito público, subjetivo, social e fundamental (Constituição da República Federativa do Brasil, 1988).

Araújo (2017) amplia a análise dos documentos legais em relação ao atendimento escolar ao doente ao verificar marcos importantes para tal serviço. De acordo com a autora, apesar da Constituição (Constituição da República Federativa do Brasil, 1988) ser um marco para a obrigatoriedade da educação, ela não cita o atendimento escolar hospitalar propriamente dito. Contudo, de acordo com o art. 206 da citada lei, o ensino obrigatório deve ser ministrado com base nos princípios da igualdade de condiçóes para o acesso e permanência na escola. Portanto, é dever do Estado fornecer acesso à educação para todos, inclusive à populaçáo doente.

Outra fundamentação legal para este tipo de atendimento, observada por Araújo (2017), é o Estatuto da Criança e do Adolescente (ECA), publicado em 1990, cujo art. 57 preconiza que "o poder público estimulará pesquisas, experiências e novas propostas relativas 
a calendário, seriação, currículo, metodologia, didática e avaliação, com vistas à inserção de crianças e adolescentes excluídos do ensino fundamental obrigatório" (Lei Federal no 8.069, 1990). Assim, o ECA contempla a possibilidade de adequação necessária para que o atendimento escolar hospitalar seja viabilizado. Araújo (2017) aponta o ECA como marco legal para esse tipo de atendimento e, assim sendo, como a primeira normatização jurídica nacional.

No ano de 1995, foi publicada a Resolução $n^{\circ} 41$, pelo Conselho Nacional dos Direitos da Criança e do Adolescente, que trata dos direitos da criança e do adolescente hospitalizados. De acordo com o direito 9, toda criança e adolescente hospitalizado tem "direito a desfrutar de alguma forma de recreação, programas de educação para a saúde, acompanhamento do curriculum escolar, durante sua permanência hospitalar” (Resolução no 41, 1995). Para Araújo (2017), trata-se da primeira legislação nacional que explicita notoriamente o direito à educação para a criança e para o adolescente doente, mas ainda assim não cita a expressão classe hospitalar ou escola hospitalar.

Com a promulgação da Lei de Diretrizes e Bases da Educação Nacional (Lei no 9.394, 1996), se estabelece, no art. 58, que "o atendimento educacional será feito em classes, escolas ou serviços especializados, sempre que, em função das condiçóes específicas dos alunos, não for possível a sua integração nas classes comuns de ensino regular” (Lei no 9.394, 1996). Já em 2001, foram instituídas as Diretrizes Nacionais para a Educação Especial na Educação Básica, por meio da Resolução n 2, de 11 de setembro de 2001. Conforme o artigo 13:

Art. 13. Os sistemas de ensino, mediante ação integrada com os sistemas de saúde, devem organizar o atendimento educacional especializado a alunos impossibilitados de frequentar as aulas em razão de tratamento de saúde que implique internação hospitalar, atendimento ambulatorial ou permanência prolongada em domicílio.

$\$ 1^{\circ}$ As classes hospitalares e o atendimento em ambiente domiciliar devem dar continuidade ao processo de desenvolvimento e ao processo de aprendizagem de alunos matriculados em escolas da Educação Básica, contribuindo para seu retorno e reintegração ao grupo escolar, e desenvolver currículo flexibilizado com crianças, jovens e adultos não matriculados no sistema educacional local, facilitando seu posterior acesso à escola regular. (Resolução $\mathrm{CEB} / \mathrm{CNE}$ n$^{\circ} 2,2001$ ).

Percebe-se aqui outro marco legal sobre o atendimento escolar ao doente no Brasil que nomeia este tipo de atendimento como classe hospitalar. Em 2002, conforme citado anteriormente, o Ministério da Educação publicou o documento Classe Hospitalar e Atendimento Pedagógico Domiciliar: estratégias e orientaçôes, para fornecer princípios e diretrizes para que os órgãos públicos efetivassem o atendimento educacional em ambientes hospitalares e domiciliares (Classe hospitalar e atendimento pedagógico domiciliar, 2002). A expressão classe hospitalar é utilizada em todo o documento para definir o atendimento escolar hospitalar. Entretanto, Araújo (2017) problematiza, em seção específica de seu estudo, as expressóes utilizadas para denominar o atendimento escolar hospitalar: classe hospitalar, pedagogia hospitalar e escola hospitalar. Segundo a autora, é necessário rever tais conceitos porque nem sempre eles representam o estabelecido pela legislação ou literatura da área.

Ao analisar a fundamentação legal para o atendimento escolar ao doente, Araújo (2017) critica a 
ausência de uma política nacional que busque efetivar meios de ofertar mais essas classes hospitalares, obrigando o Poder Público a dispor de recursos financeiros, humanos e materiais, garantindo assim, o direito à educaçáo de todos, inclusive, daqueles afastados da escola por motivo de saúde. (Araújo, 2017, p. 262).

Conforme a autora, uma possibilidade de normatização nacional é o Projeto de Lei $\mathrm{n}^{\circ}$ 548/2015, que tramita no Senado Federal, e que pretende incluir essa modalidade de ensino na Lei de Diretrizes e Bases da Educação.

Em seu estudo, Araújo (2017) também analisa legislaçóes dos estados sobre o atendimento escolar hospitalar. A autora levantou 34 documentos legais, distribuídos por 19 estados e no Distrito Federal entre os anos de 2000 e 2017. Segundo ela, o texto da maioria dessas legislações corresponde a simples citaçóes do atendimento escolar hospitalar nas resoluçóes de Conselhos de Educação dos estados. O estado do Paraná apresentou um total de 5 documentos legais entre 2007 e 2017. É possível encontrar legislação própria sobre a oferta desse tipo de serviço e sua regulamentaçáo apenas nos estados do Rio Grande do Norte, Santa Catarina, São Paulo e no Distrito Federal (Araújo, 2017).

É mister destacar que, apesar das legislaçóes citadas, muitos estados não têm ofertado o atendimento escolar hospitalar tal qual apregoa a normatização jurídica brasileira. Isso significa que inúmeros estudantes estão tendo seus direitos à educação e à saúde violados porque, conforme citam Matos e Mugiatti (2006), as dimensóes da educaçáo e da saúde se configuram como direitos inalienáveis do ser humano. A ausência do atendimento escolar ao doente configura exclusão social na medida em que um processo de enfermidade afasta o indivíduo da escola, devido à reclusão hospitalar ou ao tratamento da doença. Nesse sentido, esse tipo de atendimento serve como um mecanismo de equiparaçáo de oportunidades para o alunado que, por motivo de doença, necessita temporariamente do afastamento da escola regular. Trata-se de possibilidade de amparo às crianças e aos adolescentes doentes para não serem penalizados em alguns momentos da vida pela doença e pelo afastamento da escola. Para complementar, Albertoni (2014) aduz que esse alunado sente os efeitos da exclusão de forma dupla: um efeito causado pela doença e o outro pela falta de acesso à educação.

Estudos sobre a realidade do atendimento escolar ao doente em outros países situam a fundamentação legal de cada um desses contextos, podendo, assim, acrescer ao que já conhecemos e desenvolvemos no Brasil sobre essa temática específica.

No contexto canadense, Fonseca (2013) evidencia que a criança doente é atendida pelo sistema nacional de saúde do referido país e tem direito e acesso ao atendimento escolar uma vez que "o documento Canadian Charter of Rights and Freedoms que é parte do Constitutional Act (1867), revisto em 1982, regulamenta que todas as pessoas são compreendidas como cidadâs de direito universal. $\mathrm{O}$ artigo $5^{\circ}$ trata da equidade e da não discriminação de seus cidadáos, independente de raça, etnia, religiáo, cor, incapacidade, etc." (Fonseca, 2013, p. 42). Leal, Cabral e Perrealt (2010) asseguram que a problemática da criança doente e/ou com deficiência no Canadá "não é tratada apenas como um problema 'pediátrico', mas como um desafio para toda a sociedade" (p. 117). Nesse sentido, a não existência na realidade canadense 
de legislação específica para cada situação ou problema não exime o poder público da responsabilidade de atender às demandas específicas de seus cidadáos.

Menezes (2018) analisa o contexto espanhol do atendimento escolar hospitalar. No que se refere aos documentos legais, a terminologia específica de atendimento escolar hospitalar nem sempre está explicitada. Entretanto, o aluno doente é contemplado em sua escolaridade, considerando-se as normativas nacionais para o cumprimento da oferta escolar (Constitución Española, 1978), no referido país, com a formulação de documento direcionado a esse grupo específico de indivíduos (Resolución de 3 de julio, 1998) e, mais recentemente, com a promulgação de um decreto (Real Decreto Legislativo 1, 2013). Há também legislaçóes sobre o assunto desenvolvidas por regióes específicas do referido país como, por exemplo, para a Galícia (Decreto 229, 2011).

Sobre o Brasil, Menezes (2018) pontua as incongruências na nossa fundamentação legal que, por vezes, consideram o alunado doente como pessoa com necessidade especial e, assim sendo, sujeito da Educação Especial, e, em outros documentos, não se faz tal relação. Apesar desses entraves, no ano de 2007, a Secretaria de Educação do Estado do Paraná (Serviço de Atendimento à Rede de Escolarizaçáo Hospitalar, 2007) implanta o Serviço de Atendimento à Rede de Escolarização Hospitalar (SAREH) para o atendimento escolar da clientela hospitalizada que esteja nos anos finais do Ensino Fundamental e no Ensino Médio.

Independentemente de termos ou não, no âmbito Federal, fundamentação legal clara sobre o atendimento escolar hospitalar, cada estado da federação e, até mesmo uma cidade, por meio do governo local (municipal) e das secretarias pertinentes, conforme explicitado por Pacheco (2017), Araújo (2017) e por Menezes (2018), pode formular tanto legislaçóes quanto documentos específicos para respaldar o atendimento escolar aos doentes. A seguir apresentamos a análise comparativa dos materiais até aqui descritos.

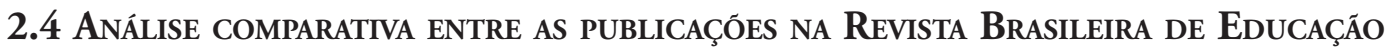 ESPECIAL, OS ENCONTROS NACIONAIS E INFORMATIVOS SEMESTRAIS E AS PRODUÇÓES ACADÊMICAS SOBRE LEGISLAÇÓES PERTINENTES AO ATENDIMENTO ESCOLAR HOSPITALAR}

O Quadro 1 a seguir resume os resultados detalhados nos itens anteriores, de forma a direcionar as discussóes da análise comparativa que a ele segue.

\begin{tabular}{|c|c|c|c|c|c|}
\hline & $\begin{array}{l}\text { Publicaçóes na RBEE } \\
\text { (4 no total) }\end{array}$ & $\begin{array}{c}\text { Encontros nacionais } \\
\quad(9 \text { no total })\end{array}$ & $\begin{array}{r}I \\
(35 \mathrm{e} \\
\end{array}$ & $\begin{array}{l}\text { os } \\
\text { total) } \\
\text { tol }\end{array}$ & Legislaçáo \\
\hline Descrição & $\begin{array}{l}2002 \text { Fonseca } \\
2011 \text { Barros, Gueudevil- } \\
\text { le e Vieira } \\
2013 \text { Saldanha e Simóes; } \\
\text { e Xavier et al. }\end{array}$ & $\begin{array}{l}2000 \text { Rio de Janeiro } \\
2002 \text { Goiânia } \\
\text { 2004 Salvador } \\
\text { 2005 Porto Alegre } \\
2007 \text { Curitiba } \\
\text { 2009 Niterói } \\
\text { 2012 Belém } \\
\text { 2014 São Paulo } \\
2015 \text { Curitiba }\end{array}$ & $\begin{array}{l}2000 \\
2002 \\
2004 \\
2006 \\
2008 \\
2010 \\
2012 \\
2014 \\
2016\end{array}$ & $\begin{array}{l}2001 \\
2003 \\
2005 \\
2007 \\
2009 \\
2011 \\
2013 \\
2015 \\
2017\end{array}$ & $\begin{array}{l}1988 \text { Constituição } \\
1990 \text { ECA } \\
1995 \text { Resolução n }{ }^{\circ} 41 \\
1996 \text { LDB } \\
2001 \text { Resoluçăo no } 2 \\
2002 \text { Documento MEC } \\
2015 \text { Projeto de Lei n } 548\end{array}$ \\
\hline
\end{tabular}




\begin{tabular}{|c|c|c|c|c|}
\hline Contribuiçóes & $\begin{array}{l}\text { - Abertura para } \\
\text { divulgaçáo de pesquisas } \\
\text { desenvolvidas na área } \\
\text { do atendimento escolar } \\
\text { hospitalar. }\end{array}$ & $\begin{array}{l}\text { - Apresentaçōes e reuniōes } \\
\text { sáo pautadas e realizadas nos } \\
\text { encontros. } \\
\text { - Espaço para trocas e com- } \\
\text { partilhamentos. } \\
\text { - O caráter itinerante do } \\
\text { evento amplia a possibilidade } \\
\text { de participaçáo dos docentes } \\
\text { espalhados no país. }\end{array}$ & $\begin{array}{l}\text { - Mais circunscritos } \\
\text { à atençâao escolar } \\
\text { hospitalar e veiculam } \\
\text { conteúdos diretamente } \\
\text { relacio-nados ao tema. } \\
\text { - Divulgação demo- } \\
\text { crática (acesso virtual e } \\
\text { gratuito) }\end{array}$ & $\begin{array}{l}\text { - Promulgação de legis- } \\
\text {-laçáo específica em } 2001 \text { e de } \\
\text { orientaçốes em 2002, enquanto } \\
\text { outros países nem contam com } \\
\text { legislaçốes próprias ainda. }\end{array}$ \\
\hline Entraves & $\begin{array}{l}\text { - Necessidade de estudos } \\
\text { críticos e problemati- } \\
\text { zadores da realidade do } \\
\text { atendimento escolar } \\
\text { hospitalar para entendi- } \\
\text { mento da modalidade e } \\
\text { respaldar a fundamenta- } \\
\text { çáo legal. }\end{array}$ & $\begin{array}{l}\text { - Parece se prestar para apenas } \\
\text { divulgar a produção acadê- } \\
\text { mica dos participantes sem, } \\
\text { necessariamente, a-crescer } \\
\text { conteúdo significativo ou } \\
\text { relevante para a área de } \\
\text { escolarizaçáo do doente. } \\
\text { - Temáticas mais abrangentes } \\
\text { e vagas. } \\
\text { - Tempo de divulgaçăo curto } \\
\text { para viabilizar a participaçáo } \\
\text { de docentes das escolas em } \\
\text { hospitais. }\end{array}$ & - & $\begin{array}{l}\text { - Apesar das legislaçóes, pouca é } \\
\text { a oferta desse atendimento pelos } \\
\text { esta-dos brasileiros. } \\
\text { - Cada estado ou até mesmo o } \\
\text { município pode formular legis- } \\
\text { laçóes e documentos específicos } \\
\text { para o atendimento escolar } \\
\text { hospitalar. }\end{array}$ \\
\hline
\end{tabular}

Quadro 1. Análise comparativa entre publicaçóes, edições realizadas do encontro, publicaçôes do informativo semestral e legislaçóes sobre atendimento escolar hospitalar Fonte: Elaboração própria.

$\mathrm{Na}$ análise comparativa dos dados levantados anteriormente e resumidos no Quadro 1 , percebe-se que o primeiro encontro nacional e os primeiros informativos publicados foram anteriores à primeira legislação específica sobre o atendimento escolar ao doente (Resolução CEB/ $\left.\mathrm{CNE} \mathrm{n}^{\circ} 2,2001\right)$. Essas iniciativas estavam contempladas em legislaçóes publicadas anteriormente à obrigatoriedade do Poder Público prover a educação ao doente, como garantia de seus direitos fundamentais [Constituição (Constituição da República Federativa do Brasil, 1988), ECA (Lei Federal no 8.069, 1990), Resoluçấo no 41 (Resolução no 41, 1995) e LDB (Lei no 9.394, 1996)].

Após as publicações da resolução (Resolução $\mathrm{CEB} / \mathrm{CNE} \mathrm{n}^{\circ}$ 2, 2001) e do documento com orientações específicas para atendimento escolar ao doente (Classe hospitalar e atendimento pedagógico domiciliar, 2002), os encontros nacionais e os informativos se solidificaram nacionalmente, apesar das críticas tecidas no quadro comparativo.

As análises de Fonseca (2002), Barros, Gueudeville e Vieira (2011), Saldanha e Simões (2013) e de Xavier et al. (2013) ponderam a necessidade de estudos tanto críticos quanto problematizadores da realidade do atendimento escolar hospitalar com vistas a melhor entender e solidificar essa área do conhecimento e para respaldar a sua fundamentação legal. Estudos comparativos de desempenho escolar de alunos que, com o advento da doença conseguiram (ou como conseguiram) manter a escolaridade em relação àqueles que não tiveram a mesma oportunidade e daqueles que retornam à escola de origem após a vivência escolar no hospital, não tem sido realizados, mas, teriam grande relevância, quaisquer que fossem os resultados, para delimitar essa área temática, definir sua abrangência assim como os papeis dos profissionais nela envolvidos. 
A divulgação da legislação nacional pertinente ao atendimento escolar ao doente se faz presente na publicação dos informativos semestrais e promove o compartilhamento de informaçóes importantes para estudantes, pesquisadores e docentes das escolas em hospitais. Infelizmente, apesar da legislação específica, uma minoria de escolas em hospitais no contexto brasileiros cumpre com a determinação legal. Após um hiato de tempo, vemos em 2015, a proposição de um projeto de lei que inclua, explicitamente, na Lei de Diretrizes e Bases da Educação Nacional, o atendimento escolar ao doente. As publicaçóes sobre a educação dos doentes na Revista Brasileira de Educação Especial contribuem com essa área.

Outra maneira de fomentar e qualificar a discussão sobre legislação específica para esse atendimento seria nos Encontros Nacionais. No entanto, tais encontros têm se resumido mais aos relatos de experiências individuais e divulgação de produção acadêmica, sem fomentar discussão e troca de experiências entre os pares para fortalecimento da área com proposição de documentos diversos e cobranças sistemáticas aos órgãos responsáveis para implantação de mais escolas hospitalares. Os estudos de Pacheco (2017), Araújo (2017) e Menezes (2018) não constam do quadro anterior porque são citados nos demais itens deste artigo.

\section{Consideraçótes finais}

As quatro publicaçóes sobre o atendimento escolar hospitalar que, até o momento, se fazem presentes na Revista Brasileira de Educação Especial, são relevantes porque se reportam a estudos que, se buscados individualmente, seriam difíceis de serem acessados e/ou poderiam passar despercebidos. Entretanto, no que se refere ao número pequeno de artigos nesse periódico específico, cabe uma análise futura criteriosa para entender os reais motivos do fato. Mesmo assim, a análise desses artigos nos fez revisitar outros documentos sobre a temática do atendimento escolar ao doente que nos ajudaram a tecer as reflexóes aqui citadas.

Essa modalidade de ensino requer uma introspecção que pode não assegurar o caminho mais adequado a seguir para garantir tanto o acesso quanto a manutenção e o êxito escolar do alunado doente, mas, sim, pode indicar o que evitar para que o atendimento escolar hospitalar não seja confundido com outras iniciativas desenvolvidas com os doentes no contexto hospitalar e, principalmente, para que não seja negligenciada, mesmo considerando que o alunado doente não é apenas cognição, mas constituído por seres humanos com questóes sociais, emocionais e clínicas que também precisam ser assistidas.

No âmbito Federal do contexto legal brasileiro atual, a documentação, especificamente voltada à Educação Especial, não explicita se o alunado doente faz ou não parte dessa área específica. Mesmo assim, alguns estados e prefeituras tem normatizado o atendimento escolar ao doente, viabilizando tanto o acesso aos processos de desenvolvimento e de aprendizagem durante o tratamento da enfermidade quanto o retorno dele para a escola de origem após recuperação da saúde. Nesse sentido, temos como exemplos o Programa de Escolarização Hospitalar (PEH) da Secretaria Municipal de Educação da Prefeitura de Curitiba (PR), citado por Pacheco (2017), e o Serviço de Atendimento à Rede de Escolarização Hospitalar (SAREH) da Secretaria de Educação do Estado do Paraná, descrito por Menezes (2018). A iniciativa dessas secretarias vai de encontro ao que observamos na realidade de outros países, como o Canadá e a Espanha, que garantem o atendimento escolar ao doente, independentemente de legislação nacional específica para esse 
fim. As normativas de implantação e de funcionamento dessa modalidade de ensino podem, inclusive, ser definidas pela localidade (estado, município, região) que delas precise.

Entretanto, pensando em uma normativa nacional adequada à educação do alunado doente, somente em novembro de 2017, após quase duas décadas de promulgação de aporte legal para o atendimento escolar hospitalar (Resolução CEB/CNE n 2, 2001; Classe hospitalar e atendimento pedagógico domiciliar, 2002), é que o Governo Federal, no âmbito de seu Ministério da Educação, propôs edital ${ }^{10}$ para levantamento legal e de práticas relacionadas ao atendimento escolar hospitalar e domiciliar tanto no âmbito Federal quanto nos estados e nos municípios brasileiros, retomando a trajetória já existente ou inaugurando uma nova com o foco na compilação de informações que subsidiem a fundamentação legal para esse contexto escolar específico.

Problematizamos se, a partir desse levantamento de aspectos legais e de práticas relacionadas ao atendimento escolar da clientela doente nas esferas Federal, estaduais e municipais, teremos uma legislação que, independentemente de sua efetiva adequação a cada escola hospitalar ou atendimento domiciliar, será acatada e implementada pelas partes envolvidas. Será que falta uma legislação adequada ou faltam tanto a consciência da relevância dessa modalidade de ensino quanto a fiscalização pelos órgãos específicos para o cumprimento dela?

$\mathrm{Na}$ medida em que a escola no hospital se perceba de alguma forma respaldada legalmente, poderá definir claramente seu papel e o exercício docente também se configurará. Assim, não apenas o direito de acesso do aluno doente à escolarização estará garantido, mas se dará eficientemente, se desdobrando tanto no retorno quanto na inserção adequados e exitosos na escola de origem. Até o momento, não parece que o atendimento escolar hospitalar, considerando a fundamentação legal específica e geral apontada no presente texto, tenha transitado de acordo com a normativa oficial. A impressão que se tem é que a normativa tem sido negligenciada e desconsiderada, como se não tivesse validade nacional, o que é uma pena já que se empreendeu tempo para formulá-la no passado e, conforme citamos anteriormente, espera-se que não se repita o mesmo com o advento do levantamento possivelmente já em andamento.

A pesquisa precisa contribuir para com mudanças e melhorias. Se não perseguirmos isso, teremos na atividade docente no ambiente hospitalar tão pouco reconhecimento quanto o que já observamos em boa parte das instituiçóes de ensino. A educação não pode prescindir de reagir às mazelas a ela impostas, e isso vale também para as modalidades mais específicas, como é o caso do atendimento escolar ao doente.

\section{REFERÊNCIAS}

Albertoni, L. C. (2014). A inclusão escolar de alunos com doenças crônicas: Professores e gestores dizem que... Curitiba: Appris.

Araújo, C. C. A. C. A. (2017). Atendimento escolar em ambiente hospitalar: Um estudo de caso do estado de São Paulo (Dissertação de Mestrado). Escola de Governo Professor Paulo Neves de Carvalho, Fundação João Pinheiro, Belo Horizonte, MG, Brasil.

\footnotetext{
${ }^{10}$ Edital sobre o atendimento escolar hospitalar e domiciliar (Projeto 914BRZ1148 Edital No 12/2017-Republicação). O detalhamento da proposta está disponível nos endereços: www.mec.gov. $b r$ (acesso à informaçáo/seleção de consultores/2017), http:// app3.brasilia.unesco.org/vagasubo/ (vagas em projetos da UNESCO no Brasil) ou, ainda, em www.brasilia.unesco.org/vagasprojetos.
} 
Bardin, L. (1979). Análise de conteúdo. Lisboa: Ediçôes 70.

Barros, A. S. S., Gueudeville, R. S., \& Vieira, S. (2011). Perfil da publicação científica brasileira sobre a temática da classe hospitalar. Revista Brasileira de Educaçâo Especial, 17(2), 335-354.

Classe hospitalar e atendimento pedagógico domiciliar: Estratégias e orientaçóes (2002). Secretaria de Educação Especial. Brasília: MEC; SEESP.

Constitución Española (1978). Recuperado em 12 de fevereiro de 2018 de http://www.congreso.es/consti/

Constitutional Act, 1867. Recuperado em 3 de fevereiro de 2018 de http://laws-lois.justice.gc. ca/eng/ Const/FullText.html

Constituição da República Federativa do Brasil de 1988. Recuperado em 10 de fevereiro de 2018 http:// www.planalto.gov.br/ccivil_03/constituicao/constituicaocompilado.htm

Decreto 229/2011, de 7 de diciembre, por el que se regula la atención a la diversidad del alumnado de los centros docentes de la Comunidad Autónoma de Galicia en los que se imparten las enseñanzas establecidas en la Ley orgánica 2/2006, de 3 de mayo, de educación. DOG, Miércoles, núm. 242. Recuperado em 5 de fevereiro de 2018 de http://www.xunta.gal/dog/Publicados/2011/20111221/ AnuncioC3F1-151211-9847_es.html

Decreto-Lei $n^{\circ}$ 1.044, de 21 de outubro de 1969. Dispóe sobre o tratamento excepcional para os alunos portadores das afecçóes que indica. Texto - Publicação Original. Recuperado em 4 de fevereiro de 2018 de http://www2.camara.leg.br/legin/fed/declei/1960-1969/decreto-lei-1044-21-outubro1969-373565-norma-pe.html

Fonseca, E. S. (I 999). Classe hospitalar: Ação sistemática na atenção às necessidades pedagógicoeducacionais de crianças e adolescentes hospitalizados. Temas sobre Desenvolvimento, 8(44), 32-37.

Fonseca, E. S. (2002). Implantação e implementação de espaço escolar para crianças hospitalizadas. Revista Brasileira de Educação Especial, 8(2), 205-222.

Fonseca, E. S. (2013). Delimitação da demanda educacional da criança com necessidade especial de saúde (Relatório Pós-doutorado). Conselho de Pós-Graduação e Pesquisa em Enfermagem do Programa de Pós-Graduação e Pesquisa da Escola de Enfermagem Anna Nery, Universidade Federal do Rio de Janeiro, Rio de Janeiro, RJ, Brasil.

Fonseca, E. S. (20 16). Análises dos Encontros Nacionais sobre Atendimento Escolar Hospitalar (2000-2016) e suas possiveis contribuiçôes para esta temática especifica. $15 \mathrm{p}$. Mimeo.

Fonseca, E. S. (20 I7). Informativos Semestrais sobre Atendimento Escolar Hospitalar: Consideraçóes após 35 ediçóes. 17 p. Mimeo.

Fonseca, E. S., \& Ceccim, R. B. (1999). Atendimento pedagógico educacional hospitalar: Promoção do desenvolvimento psíquico e cognitivo da criança hospitalizada. Temas sobre Desenvolvimento, 7(42), 24-36.

Lakatos, E. M., \& Marconi, M. A. (2001). Fundamentos de metodologia cientifica (4a ed.). São Paulo: Atlas.

Leal, R. J., Cabral, I. E., \& Perreault, M. (2010). Experiência Brasil-Canadá no cuidado social e na saúde da criança com necessidades especiais: Aproximações e distanciamentos. Interfaces Brasil/Canadá - Revista Brasileira de Estudos Canadenses, 11, 95-119.

Lei Federal no 8.069, de 13 de julho de 1990. Dispóe sobre o Estatuto da Criança e do Adolescente e dá outras providências. Recuperado em 10 de fevereiro de 2018 de http://www.planalto.gov.br/ CCIVIL_03/leis/L8069.htm 
Lei no 9.394, de 20 de dezembro de 1996. Estabelece as diretrizes e bases da educação nacional. Recuperado em 15 de fevereiro de 2018 de http://www.planalto.gov.br/ccivil_03/LEIS/L9394.htm

Libâneo, J. C., \& Pimenta. S. G. (1999). Formação de profissionais da educação: Visão crítica e perspectiva de mudança. Educação \& Sociedade, 20(68), 239-277.

Matos, E. L. M., \& Mugiatti, M. M. T. F. (2006). Pedagogia hospitalar: A humanização integrando educação e saúde (2a ed.). Petrópolis, RJ: Vozes.

Menezes, C. V. A. (2018). Atendimento Escolar Hospitalar e Domiciliar: Estudo comparado das politicas educacionais do ParanálBrasil e da GalícialEspanha (Tese de Doutorado). Programa de PósGraduação em Educação, Setor de Educação, Universidade Federal do Paraná, Curitiba, PR, Brasil.

Mugiatti, M. M. T. F. (1989). Hospitalização Escolarizada: Uma nova alternativa para o escolar-doente (Dissertação de Mestrado). Pontifícia Universidade Católica do Rio Grande do Sul, Programa de Pós-Graduação em Serviço Social, Porto Alegre, RS, Brasil.

Oliveira, M. M. (2007). Como fazer pesquisa qualitativa. Petrópolis: Vozes.

Pacheco, M. C. P. (2017). Escolarização hospitalar e a formação de professores na Secretaria Municipal da Educação de Curitiba no periodo de 1998 a 2015 (Dissertação de Mestrado). Pontifícia Universidade Católica do Paraná, Curitiba, PR, Brasil.

Real Decreto Legislativo 1/2013, de 29 de noviembre, por el que se aprueba el Texto Refundido de la Ley General de derechos de las personas con discapacidad y de su inclusión social. Boletín Oficial del Estado, Madrid, n. 289. Recuperado em 3 de fevereiro de 2018 de http://www.boe.es/buscar/ pdf/2013/BOE-A-2013-12632-consolidado.pdf

Resolução CEB/CNE $n^{\circ}$ 2, de 11 de fevereiro de 2001. Diretrizes Nacionais para a Educação Especial na Educação Básica. Brasília: MEC. Recuperado em 4 de fevereiro de 2018 de http://portal.mec.gov. br/seesp/arquivos/pdf/diretrizes.pdf.

Resolução no 41, de 13 de outubro de 1995. Brasília: Imprensa Oficial. Recuperado em 10 de fevereiro de 2018 de http://www.mprs.mp.br/infancia/legislacao/id2178.htm

Resolución de 3 de julio de 1998, da publicidad al Convenio suscrito entre el Ministerio de Educación y Cultura, el Ministerio de Sanidad y Consumo y el Instituto Nacional de la Salud para la atención educativa a los niños hospitalizados. Boletín Oficial del Estado, Madrid, n. 179, pp. 25610 a 25612. Recuperado em 5 de fevereiro de 2018 de https://www.boe.es/diario_boe/txt.php?id=BOE-A-1998-18120

Saldanha, G. M. M. M., \& Simóes, R. R. (2013). Educação escolar hospitalar: O que mostram as pesquisas? Revista Brasileira de Educação Especial, 19(3), 447-464.

Serviço de Atendimento à Rede de Escolarização Hospitalar (SAREH) (2007). Curitiba: SEED-PR. Recuperado em 10 de fevereiro de 2018 de http://www.portugues.seed.pr.gov.br/arquivos/File/sareh/sareh.pdf

Xavier, T. G. M., Araújo, Y. B. de, Reichert, A. P. dos S., \& Collet, N. (2013). Classe hospitalar: Produção do conhecimento em saúde e educação. Revista Brasileira de Educação Especial, 19(4), 611-622.

Recebido em: 03/03/2018

Reformulado em: 16/05/2018

Aceito em: 09/06/2018 